\title{
Covid Politics
}

Murmurations:

Journal of

Transfórmative

Systemic

Practice
Jasmine T. Chin

Illustration by Hayley Clarke

\section{Volume 3 \\ Issue 1 \\ Autumn 2020}

Keywords:

Covid politics, Black Lives Matter, Covid19, coronavirus, masks, poetry

Citation Link

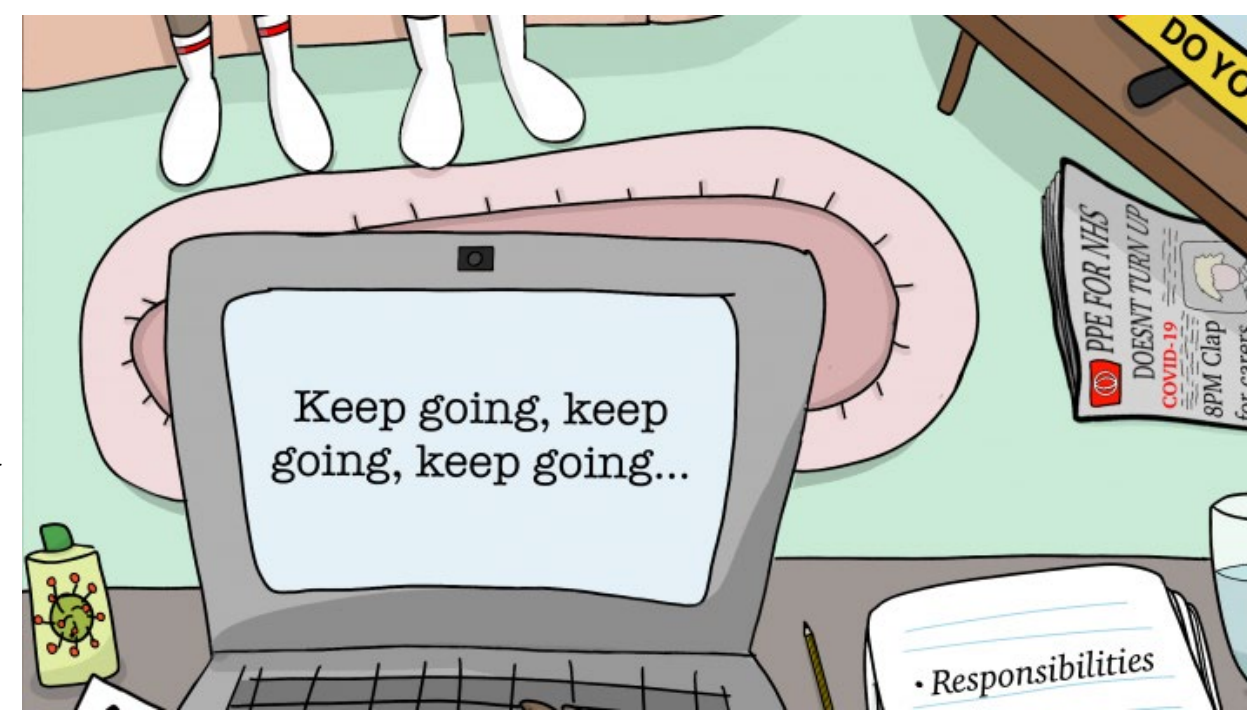

Knock knock

"Who's there?"

Covid politics

"Covid politics?...What? Who?"

Ha! You'll see...

Oi you!

Citizen!

"Yes Covid Politics?"

It's your duty, not ours to

save lives

To hide lies

Whatever your circumstances.

You will clap

to run the country

Into a ground swell of positivity

Heroism our chosen protection

from vulnerability 
Feeding the national pride

To keep the economy alive

for our favoured few.

It's not new

Oi you!

Manager!

Lead from the front

Push up from the rear

of your front room.

Ground down in your seat

You'll take the heat, to

Keep those voices of doom at bay.

You can do it! Keep going! What a team!

Innovate, maintain!

Feel as I say. Not as I do.

Oi you! Therapist!

Zoom into the mirrored room

It's you in there too!

Focus, perform, attune

To everything and nothing

All at once.

Rapid adaptation

Framed perfection

Off screen exhaustion.

Smile!

Oi You! Mother!

Nurture, love, educate

Soothe, motivate, confiscate.

Replicate.

Day after day after day

After all

Curriculum success

Is the way to redress

The imbalance. Isn't it?

More to the point engage, create, bake

The guilt we'll disseminate

For their sake

Not ours.

No furlough for this task.

Oi you! Supervisor!

Do all of the above 
Once or twice a month

(But leave out the love

This is science

In case you needed a clue)

Oi you! Black Life!

We hear, we know.

We kneel

Alongside you

To mask the real

Truth we won't tolerate.

Diabetes, heart disease,

Vitamin D

Our scientist agree

It's your responsibility

That's key.

Eat right, socially distanced sunlight

Let's leave the PPE.

But please Speak Aloud

Explain, contain

Share the profound

Pain to those who'll say

They never knew.

"Hey You! Covid Politics!

I see you unmasked

Illuminating the vast

Gulf where diseased actions flourish

Yes Earth is at peace

Free of our rubbish.

But senses are heightened

Multiple lives taken

Forsaken by more than your germs

Will others choose

to see you with me?

We'll see..."

\section{Citation}

Chin, Jasmine T. (2020). Covid Politics. Murmurations: Journal of Transformative Systemic Practice, 3, 1, 13-14. https://doi.org/10.28963/3.1.5 